\title{
Annealing effects on the crystallization and shape memory effect of $\mathrm{Ti}_{50} \mathrm{Ni}_{25} \mathrm{Cu}_{25}$ melt-spun ribbons
}

\author{
S.H. Chang ${ }^{a}$, S.K. Wu ${ }^{a}, *$ H. Kimura ${ }^{b}$ \\ ${ }^{a}$ Department of Materials Science and Engineering, National Taiwan University, 1 Roosevelt Road, Sec. 4, Taipei 106, Taiwan \\ ${ }^{\mathrm{b}}$ Institute for Materials Research, Tohoku University, Sendai 980-8577, Japan \\ Received 5 September 2005; accepted 5 May 2006 \\ Available online 10 July 2006
}

\begin{abstract}
As-spun $\mathrm{Ti}_{50} \mathrm{Ni}_{25} \mathrm{Cu}_{25}$ ribbon is fully amorphous with a lower wavenumber $Q_{\mathrm{p}}$ than the amorphous $\mathrm{Ti}-\mathrm{Ni}$ alloys owing to its high $\mathrm{Cu}$ content. Both crystallization activation energy $E_{\mathrm{a}}$ and onset temperature $T_{x}$ for $\mathrm{Ti}_{50} \mathrm{Ni}_{25} \mathrm{Cu}_{25}$ ribbon are lower than those for $\mathrm{Ti}_{50} \mathrm{Ni}_{50}$ ribbon, indicating that the former has lower thermal stability. When $\mathrm{Ti}_{50} \mathrm{Ni}_{25} \mathrm{Cu}_{25}$ ribbon is annealed at $500{ }^{\circ} \mathrm{C}$ for 3 min, the initial as-crystallized grains contain a low $\mathrm{Cu}$ content and perform a prominent shape memory effect. Through prolonging the annealing time, more grains are crystallized in the ribbon but it becomes more fragile and its recoverable strain decreases. This is due to the increasing $\mathrm{Cu}$ content in the crystallized grains. Crystallized $\mathrm{Ti}_{50} \mathrm{Ni}_{25} \mathrm{Cu}_{25}$ ribbon can exhibit a good shape memory effect only under appropriate annealing conditions.
\end{abstract}

(C) 2006 Elsevier Ltd. All rights reserved.

Keywords: A. Ternary alloy systems; B. Martensitic transformations; B. Shape-memory effects; C. Rapid solidification processing

\section{Introduction}

TiNi-based alloys are known as the most important shape memory alloys (SMAs) with good shape memory effect (SME), superelasticity (PE) and damping capacity (DC) [1]. Substituting $\mathrm{Cu}$ for $\mathrm{Ni}$ in binary Ti-Ni SMA has been known to lower the transformation hysteresis, the superelasticity hysteresis, and the flow stress level in the martensite state. The narrow hysteresis of $\mathrm{Ti}-\mathrm{Ni}-\mathrm{Cu}$ ternary SMAs has the potential for applications which require short response times during thermal cycling [2]. Adding $\mathrm{Cu}$ into $\mathrm{Ti}-\mathrm{Ni}$ binary SMAs also has been reported to reduce the sensitivity of the martensitic transformation start temperature, Ms, to compositional changes and to prevent $\mathrm{Ti}_{3} \mathrm{Ni}_{4}$ precipitation [2-4]. Moreover, the transformation sequence in $\mathrm{Ti}-\mathrm{Ni}-\mathrm{Cu}$ SMAs depends on the $\mathrm{Cu}$ content. For $\mathrm{Cu}$ contents below 10 at.\%, the monoclinic $\mathrm{B} 19^{\prime}$ martensite is formed on cooling from

\footnotetext{
* Corresponding author. Tel.: +88622363 7846; fax: +886223634562. E-mail address: skw@ntu.edu.tw (S.K.Wu).
}

the cubic B2 austenite. When the $\mathrm{Cu}$ content is approximately in between 10 and 15 at.\%, the two-stage transformation behavior of $\mathrm{B} 2 \leftrightarrow \mathrm{B} 19 \leftrightarrow \mathrm{B} 19^{\prime}$ is obtained where $\mathrm{B} 19$ is an orthorhombic martensite [5]. In the case of a higher $\mathrm{Cu}$ content, the second step is inhibited and only B2 $\leftrightarrow$ B19 appears $[2,6]$. Unfortunately, it was found that $\mathrm{Cu}$ additions exceeding 10 at.\% embrittle the alloy and seriously reduce the workability and shape recovery strain [2,7]. This restrains the application of high $\mathrm{Cu}$ content $\mathrm{Ti}-\mathrm{Ni}-\mathrm{Cu}$ SMAs.

In recent years, melt-spinning techniques have been utilized to fabricate high $\mathrm{Cu}$ content $\mathrm{Ti}-\mathrm{Ni}-\mathrm{Cu}$ ternary SMAs in order to avoid the aforementioned restriction of workability. $\mathrm{Ti}_{50-}$ $\mathrm{Ni}_{25} \mathrm{Cu}_{25}$ (at.\%) ribbon has been widely studied because of its small transformation hysteresis, large transformation strain, and one-stage B2 $\leftrightarrow$ B19 transformation compared to conventionally fabricated $\mathrm{Ti}-\mathrm{Ni}-\mathrm{Cu}$ wire [8]. Fabrication of $\mathrm{Ti}-\mathrm{Ni}-\mathrm{Cu}$ ternary SMA ribbons by means of the melt-spinning technique has been shown to be suitable for producing alloys with controllable amorphous or crystalline structures. Nevertheless, the as-spun $\mathrm{Ti}-\mathrm{Ni}-\mathrm{Cu}$ ribbon is amorphous and shows no SME if the ribbon is fabricated using a high cooling rate in 
the melt-spinning procedure. Therefore, a proper thermal annealing procedure is required to crystallize the as-spun amorphous ribbon. Previous studies on $\mathrm{Ti}_{50} \mathrm{Ni}_{25} \mathrm{Cu}_{25}$ ribbon focused on the microstructure of the partially or fully crystallized alloys, the precipitates generated after thermal treatment, and their effects on the martensitic transformation [8-13]. However, only little works referred to the effect of annealing on the SME and on the mechanical properties of the crystallized $\mathrm{Ti}_{50} \mathrm{Ni}_{25} \mathrm{Cu}_{25}$ ribbon [14,15]. Liu [14] stated that a $\mathrm{Ti}_{50-}$ $\mathrm{Ni}_{25} \mathrm{Cu}_{25}$ melt-spun ribbon annealed at $500{ }^{\circ} \mathrm{C}$ for $15 \mathrm{~min}$ exhibits a well-defined SME and a good superelastic shape recovery strain with low hysteresis. No other annealing condition was presented because the ribbon annealed at a temperature higher than $500{ }^{\circ} \mathrm{C}$ shows poorer mechanical properties. Cheng and Xie [15] reported the influence of the annealing temperature on the shape memory properties of a $\mathrm{Ti}_{50} \mathrm{Ni}_{25} \mathrm{Cu}_{25}$ melt-spun ribbon. They discovered that the recovery strain significantly decreases with increasing annealing temperature and proposed that the decreasing recovery strain may be due to the larger grain size and the more preferentially orientated precipitates which form at higher annealing temperature.

In view of the applications of $\mathrm{Ti}_{50} \mathrm{Ni}_{25} \mathrm{Cu}_{25}$ melt-spun ribbons, it is important to control appropriate annealing conditions to crystallize the as-spun amorphous $\mathrm{Ti}_{50} \mathrm{Ni}_{25} \mathrm{Cu}_{25}$ ribbons without deteriorating their SME properties. However, up to now, the annealing effects on the crystallization behavior and SME properties of $\mathrm{Ti}_{50} \mathrm{Ni}_{25} \mathrm{Cu}_{25}$ melt-spun ribbon have not been elucidated in detail. In this study, the amorphouscrystalline characteristics of $\mathrm{Ti}_{50} \mathrm{Ni}_{25} \mathrm{Cu}_{25}$ melt-spun ribbons annealed at $500{ }^{\circ} \mathrm{C}$ for different time intervals are investigated by means of X-ray diffraction (XRD), differential scanning calorimetry (DSC), dynamic mechanical analysis (DMA) and scanning electron microscopy (SEM) with energy dispersive spectrometry (EDS). The crystallization behavior and shape memory property of annealed $\mathrm{Ti}_{50} \mathrm{Ni}_{25} \mathrm{Cu}_{25}$ melt-spun ribbons are also discussed.

\section{Experimental procedures}

$\mathrm{ATi}_{50} \mathrm{Ni}_{25} \mathrm{Cu}_{25}$ ingot was prepared by conventional vacuum arc remelting (VAR). The ingot was re-melted six times in an argon atmosphere for homogenization. The as-melted $\mathrm{Ti}_{50-}$ $\mathrm{Ni}_{25} \mathrm{Cu}_{25}$ ingot was cut into an appropriate size and then induction-melted in an argon atmosphere in a quartz crucible at $1150{ }^{\circ} \mathrm{C}$, and subsequently ejected with pressurized argon gas onto a copper roller with a surface velocity of $42 \mathrm{~m} / \mathrm{s}$. The final ribbons were about $20 \mu \mathrm{m}$ in thickness and $1.1 \mathrm{~mm}$ in width. Thereafter, the as-spun ribbons were cut into test specimens, sealed in evacuated quartz tubes and annealed at $500{ }^{\circ} \mathrm{C}$ in a salt bath for different time intervals.

The crystallographic features of the ribbons during crystallization annealing were determined with a Philips PW 1830 XRD instrument using $\mathrm{Cu} \mathrm{K} \alpha$ radiation. The crystallization and transformation temperatures of each specimen were determined by DSC using a TA Q10 DSC equipment. Specimen weights for DSC investigations were 5-6 mg and the heating and cooling rates were $10{ }^{\circ} \mathrm{C} / \mathrm{min}$. The transformation strain during thermal cycling was measured by tensile testing under constant stress (90 MPa) using a TA 2980 DMA equipment with a tension clamp. The gauge length of each specimen was set as $10 \mathrm{~mm}$ and the heating and cooling rates were $3{ }^{\circ} \mathrm{C} / \mathrm{min}$. Microstructure observations and composition analysis for the ribbons annealed at $500{ }^{\circ} \mathrm{C}$ for different time intervals were performed with a Philips XL 30 SEM instrument equipped with an EDS unit.

\section{Experimental results}

\subsection{Crystallization of $\mathrm{Ti}_{50} \mathrm{Ni}_{25} \mathrm{Cu} u_{25}$ melt-spun amorphous ribbon}

Fig. 1 displays the XRD diffraction pattern of as-spun $\mathrm{Ti}_{50} \mathrm{Ni}_{25} \mathrm{Cu}_{25}$ ribbon. As illustrated in Fig. 1, only a broad amorphous peak appears near $2 \theta=41.8^{\circ}$. It reveals that the as-spun $\mathrm{Ti}_{50} \mathrm{Ni}_{25} \mathrm{Cu}_{25}$ ribbon is completely amorphous. The position of this broad amorphous peak can be represented by the wavenumber $Q_{\mathrm{P}}=4 \pi \sin \theta / \lambda$ which is inversely proportional to the mean nearest-neighbor distance of the localordering clusters of amorphous alloys [16]. The $Q_{\mathrm{P}}$ value calculated from Fig. 1 is plotted in Fig. 2 and is compared with the results from the rapid quenching melt-spun $\mathrm{Ti}-\mathrm{Ni}$ and $\mathrm{Ti}-\mathrm{Ni}-\mathrm{Cu}$ SMA ribbons [17], mechanical alloyed powders [16] and sputtered thin films [18,19].

Fig. 3 displays the DSC curves for $\mathrm{Ti}_{50} \mathrm{Ni}_{25} \mathrm{Cu}_{25}$ melt-spun ribbons with different heating rates to determine the crystallization activation energy. The peak temperature, $T_{\mathrm{p}}$, and the onset temperature, $T_{x}$, of crystallization are also denoted in Fig. 3. There is only one-stage of crystallization obtained in $\mathrm{Ti}_{50} \mathrm{Ni}_{25} \mathrm{Cu}_{25}$ melt-spun amorphous ribbon. The two-stage crystallization behavior of rapid quenched $\mathrm{Ti}_{70} \mathrm{Ni}_{30}$ and $\mathrm{Ti}_{60} \mathrm{Ni}_{40}$ ribbons [20] is not observed. As clearly shown in Fig. 3, the crystallization temperatures, $T_{\mathrm{p}}$ and $T_{x}$, rise with increasing heating rate. According to the results obtained in Fig. 3, the crystallization activation energy, $E_{\mathrm{a}}$, can be determined from Kissinger's relation [21]:

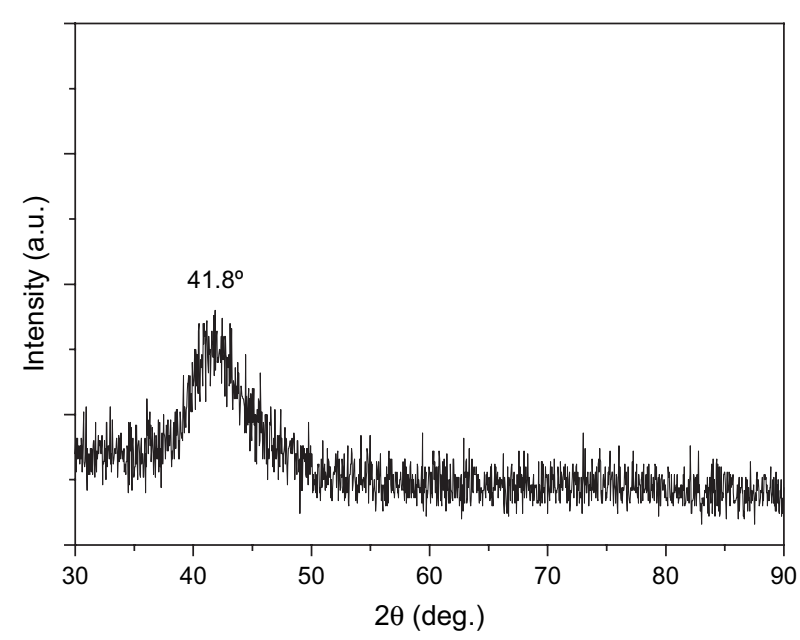

Fig. 1. XRD pattern for the as-spun $\mathrm{Ti}_{50} \mathrm{Ni}_{25} \mathrm{Cu}_{25}$ amorphous ribbon. 


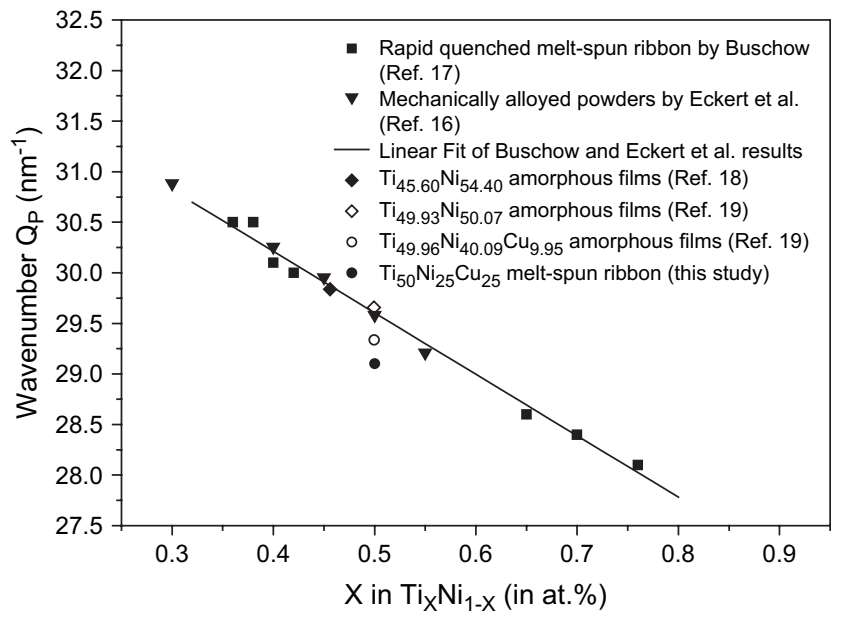

Fig. 2. Wavenumber $Q_{\mathrm{p}}$ of amorphous $\mathrm{Ti}_{50} \mathrm{Ni}_{25} \mathrm{Cu}_{25}$ melt-spun ribbon versus Ti content in comparison with the results of rapid quenched samples [17], mechanically alloyed powders [16] and sputtered films [18,19].

$\ln \left(\alpha / T_{\mathrm{p}}^{2}\right)=C-E_{\mathrm{a}} / \mathrm{R} T_{\mathrm{p}}$

where $C$ is a constant, $\alpha$ is the heating rate, $E_{\mathrm{a}}$ is the crystallization activation energy, and $\mathrm{R}$ is the gas constant. Fig. 4 plots $\ln \left(\alpha / T_{\mathrm{p}}^{2}\right)$ versus $1 / T_{\mathrm{p}}$ based on the DSC results shown in Fig. 3 for $\mathrm{Ti}_{50} \mathrm{Ni}_{25} \mathrm{Cu}_{25}$ melt-spun ribbon. The crystallization activation energy for $\mathrm{Ti}_{50} \mathrm{Ni}_{25} \mathrm{Cu}_{25}$ ribbon is calculated as $341 \mathrm{~kJ} / \mathrm{mol}$. As shown in Fig. 3, $T_{x}$ for $\mathrm{Ti}_{50} \mathrm{Ni}_{25} \mathrm{Cu}_{25}$ meltspun ribbon with the cooling rate of $30^{\circ} \mathrm{C} / \mathrm{min}$ is detected as $477^{\circ} \mathrm{C}$. This crystallization temperature, $T_{x}$, is plotted versus the $\mathrm{Ti}$ content of the $\mathrm{Ti}_{x} \mathrm{Ni}_{1-x}$ alloys in Fig. 5 with the results obtained from other studies [16-19].

\subsection{Annealing effect in $\mathrm{Ti}_{50} \mathrm{Ni}_{25} \mathrm{C} u_{25}$ melt-spun ribbon}

\subsubsection{XRD measurements}

Fig. 6(a) shows XRD results of $\mathrm{Ti}_{50} \mathrm{Ni}_{25} \mathrm{Cu}_{25}$ melt-spun ribbon annealed at $500{ }^{\circ} \mathrm{C}$ for different time intervals. As

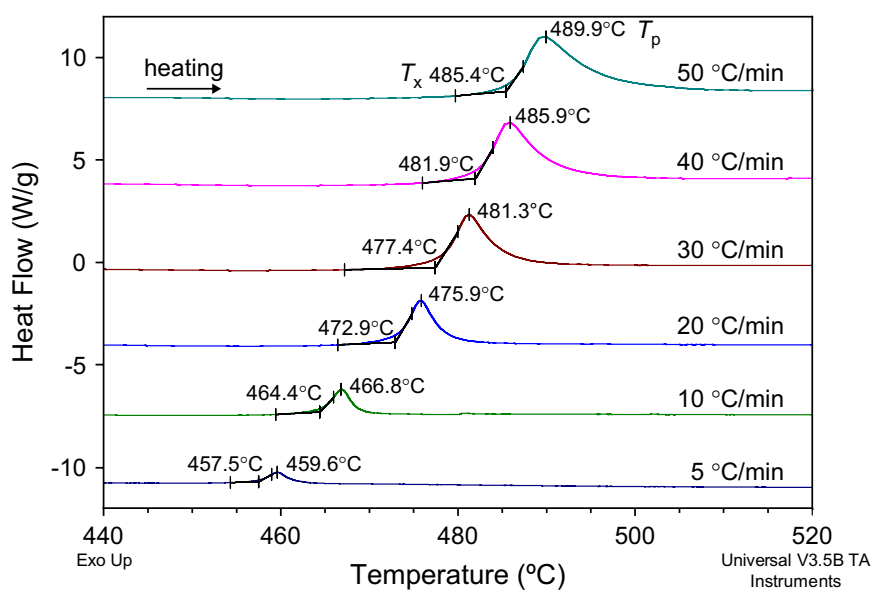

Fig. 3. DSC curves with different heating rates for $\mathrm{Ti}_{50} \mathrm{Ni}_{25} \mathrm{Cu}_{25}$ melt-spun ribbon.

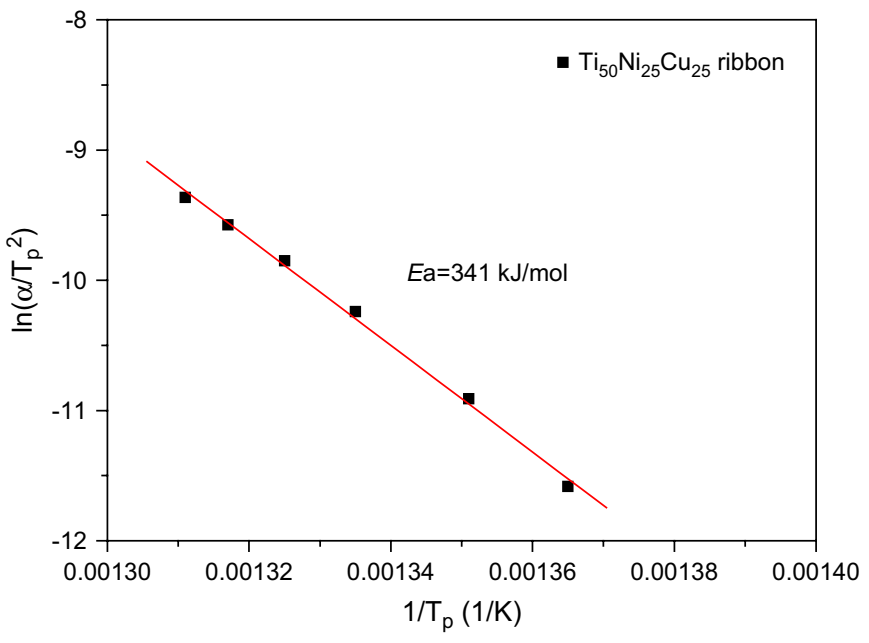

Fig. 4. Kissinger's plots for the data obtained from DSC curves in Fig. 3.

shown in Fig. 6(a), the as-spun ribbon and the ribbon annealed at $500{ }^{\circ} \mathrm{C}$ for $60 \mathrm{~s}$ are completely amorphous. When the ribbon is annealed at $500{ }^{\circ} \mathrm{C}$ for $90 \mathrm{~s}$, a small $(200)_{\mathrm{B} 2}$ peak appears at around $2 \theta=61^{\circ}$. After annealing at $500{ }^{\circ} \mathrm{C}$ for $100 \mathrm{~s}$, the intensity of the $(200)_{\mathrm{B} 2}$ peak increases. When the ribbon is annealed for $110 \mathrm{~s}$, besides the $(200)_{\mathrm{B} 2}$ peak, the other two peaks $(110)_{\mathrm{B} 2}$ and $(211)_{\mathrm{B} 2}$ develop at $2 \theta=42^{\circ}$ and $76^{\circ}$, respectively. When the annealing time is extended to $3 \mathrm{~min}$, the $(110)_{\mathrm{B} 2}$ peak becomes dominant and has a greater intensity than the others. After annealing for $60 \mathrm{~min}$, the diffraction pattern is similar to that of the ribbon annealed at $500{ }^{\circ} \mathrm{C}$ for $3 \mathrm{~min}$. However, now an extra peak $(002)_{\mathrm{B} 19}$ of $\mathrm{B} 19$ martensite appears at $2 \theta=41^{\circ}$ because a partial B2 $\rightarrow$ B19 transformation occurs at room temperature. Fig. 6(b) plots the evolution of the lattice parameter of B2 parent phase as calculated from the XRD results of $(200)_{\mathrm{B} 2}$ and $(110)_{\mathrm{B} 2}$ shown in Fig. 6(a). As indicated in Fig. 6(b), the lattice parameter of the B2

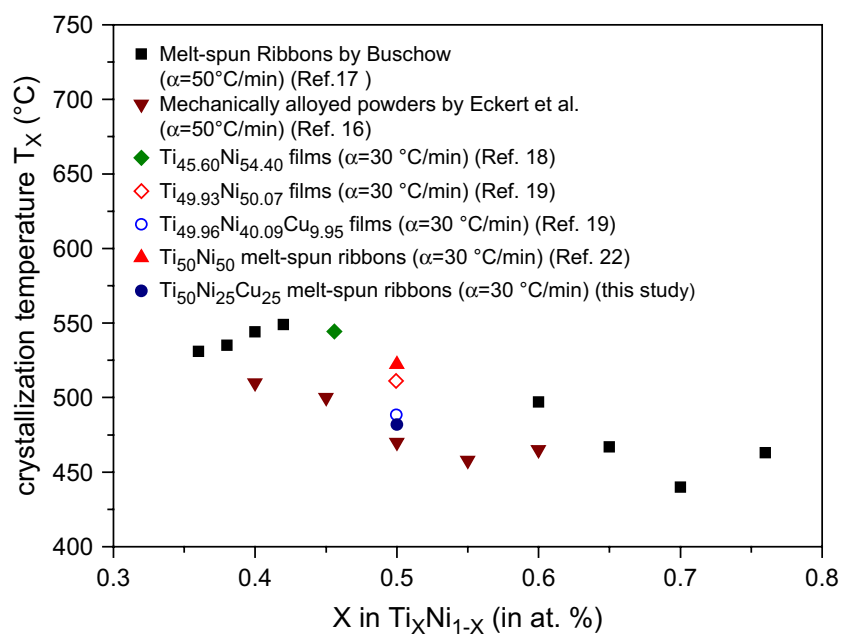

Fig. 5. Crystallization temperature, $T_{x}$, of $\mathrm{Ti}_{50} \mathrm{Ni}_{25} \mathrm{Cu}_{25}$ melt-spun ribbon versus $\mathrm{Ti}$ content in comparison with the results of rapid quenched samples [17], mechanically alloyed powders [16] and sputtered films [18,19]. 
(a)
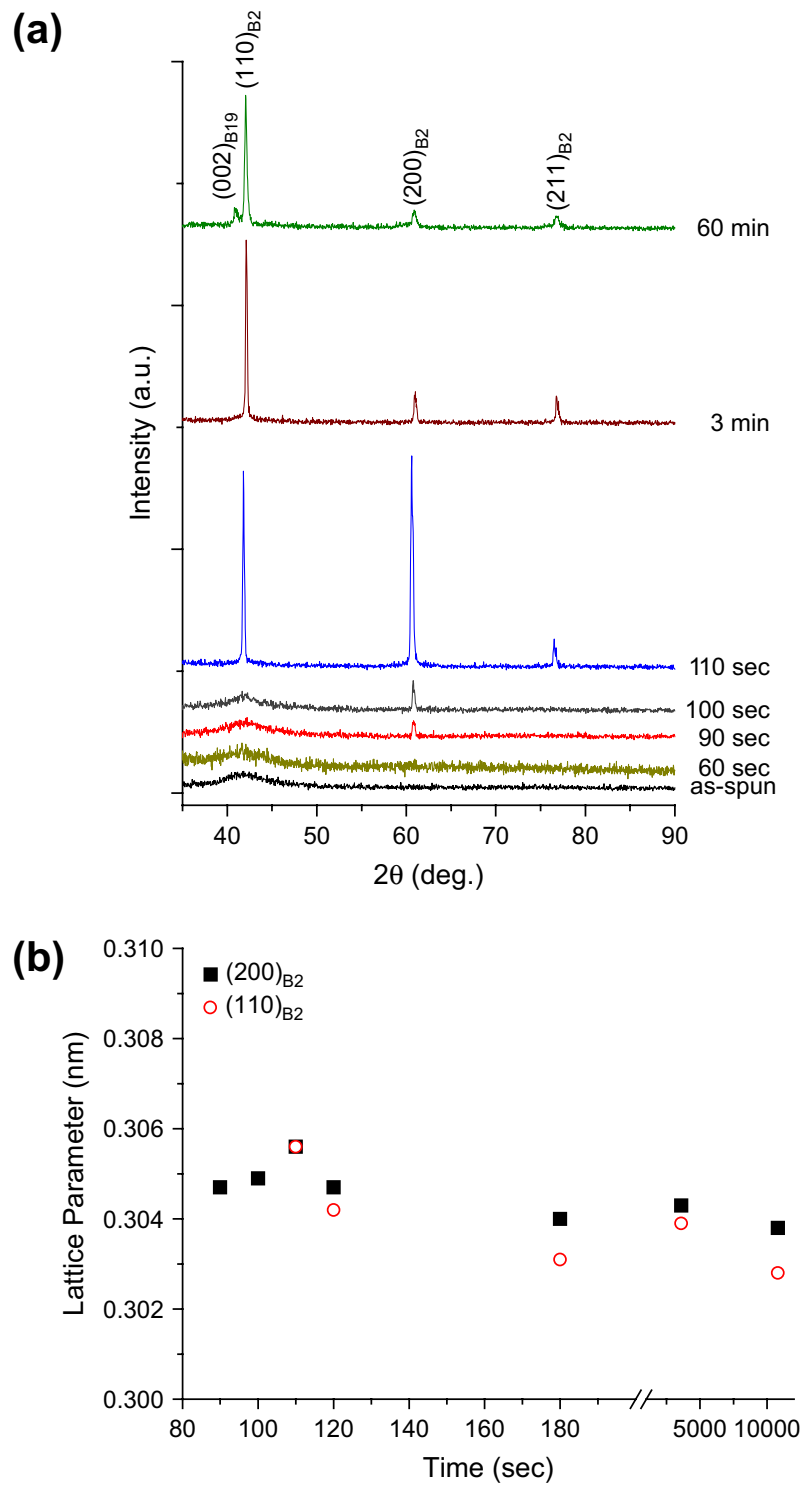

Fig. 6. (a) XRD patterns for $\mathrm{Ti}_{50} \mathrm{Ni}_{25} \mathrm{Cu}_{25}$ melt-spun ribbon annealed at $500{ }^{\circ} \mathrm{C}$ for different time intervals, and (b) change of the lattice parameter calculated form $(200)_{\mathrm{B} 2}$ and $(110)_{\mathrm{B} 2}$ shown in (a) as a function of the annealing time.

phase of $\mathrm{Ti}_{50} \mathrm{Ni}_{25} \mathrm{Cu}_{25}$ ribbon gradually decreases from $0.305 \mathrm{~nm}$ to about $0.304 \mathrm{~nm}$ with an increased annealing time.

\subsubsection{DSC results}

Fig. 7 shows the DSC results of $\mathrm{Ti}_{50} \mathrm{Ni}_{25} \mathrm{Cu}_{25}$ melt-spun amorphous ribbon annealed at $500{ }^{\circ} \mathrm{C}$ from $3 \mathrm{~min}$ to $3 \mathrm{~h}$. The measured DSC cooling and heating curves for each specimen are approximately the same, and thus only the cooling curves are discussed. As shown in Fig. 7, the specimen for each annealing time exhibits a single-stage B2 $\rightarrow$ B19 transformation in cooling. The Ms temperatures of B2 $\rightarrow$ B19 martensitic transformation and their transformation enthalpies $\Delta H$ shown in Fig. 7 are plotted in Fig. 8(a) and (b), respectively. Upon increasing the annealing time, as illustrated in Figs. 7

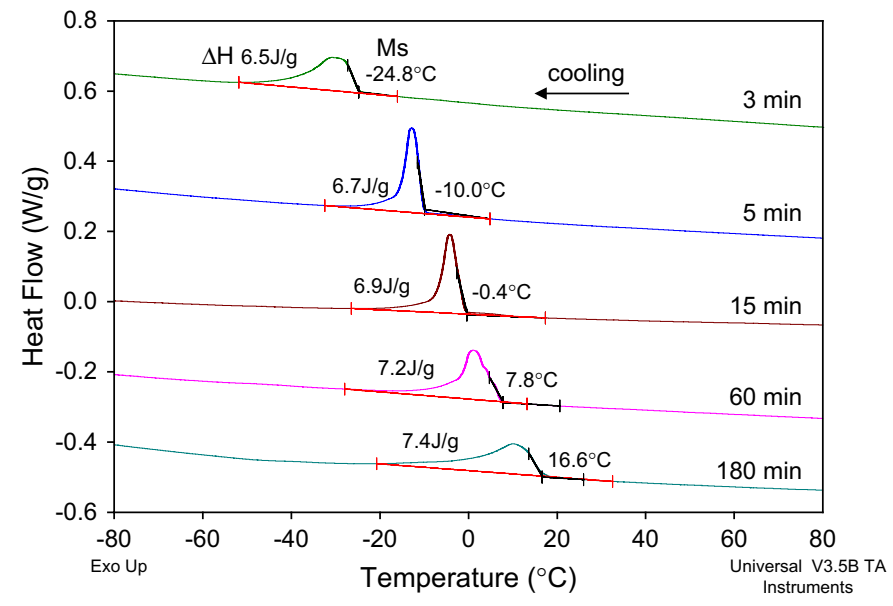

Fig. 7. DSC curves for $\mathrm{Ti}_{50} \mathrm{Ni}_{25} \mathrm{Cu}_{25}$ melt-spun ribbon annealed at $500{ }^{\circ} \mathrm{C}$ for different time intervals.

and 8, the transformation temperatures of the crystallized $\mathrm{Ti}_{50} \mathrm{Ni}_{25} \mathrm{Cu}_{25}$ melt-spun ribbon drastically shift to a higher temperatures and the corresponding $\Delta H$ value gradually increases with the prolonged annealing time. The $\Delta H$ value
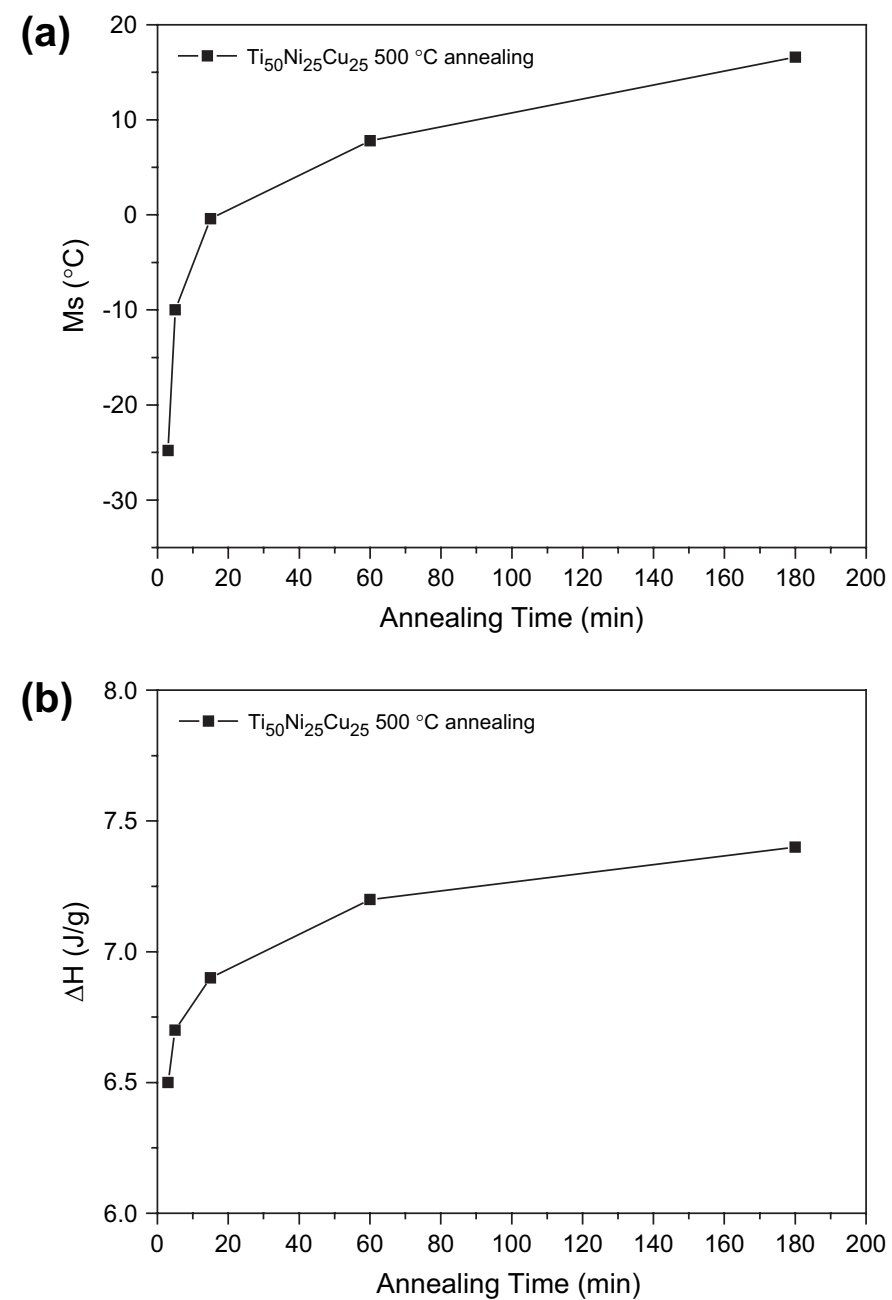

Fig. 8. Change of (a) the Ms transformation temperature and (b) the transformation enthalpy as a function of the annealing time. The data are taken from DSC curves shown in Fig. 7. 
eventually reaches about $7.5 \mathrm{~J} / \mathrm{g}$, which is lower than the normal $\mathrm{Ti}-\mathrm{Ni}-\mathrm{Cu}$ bulk alloys, say, $17.1 \mathrm{~J} / \mathrm{g}$ [5].

\subsubsection{Tensile test results}

Fig. 9(a) shows the selected strain-temperature curves under a constant stress $\left(90 \mathrm{MPa}\right.$ ) for the $\mathrm{Ti}_{50} \mathrm{Ni}_{25} \mathrm{Cu}_{25}$ melt-spun ribbon annealed at $500{ }^{\circ} \mathrm{C}$ for different time intervals. In order to compare the shape recovery effect of each specimen, only a low stress $(90 \mathrm{MPa})$ was applied to ensure that no residual deformation would be retained after the test. Fig. 9(b) plots the evolution of the measured recoverable strain from Fig. 9(a). As illustrated in Fig. 9(a) and (b), each $\mathrm{Ti}_{50} \mathrm{Ni}_{25} \mathrm{Cu}_{25}$ melt-spun ribbon exhibits a well-defined shape recovery effect when the specimen is annealed for more than $3 \mathrm{~min}$. Among them, the specimen annealed at $500{ }^{\circ} \mathrm{C}$ for $3 \mathrm{~min}$ has the maximum recoverable strain of about $2 \%$, as indicated by the double arrows in Fig. 9(a). When the annealing time is prolonged, however, the recoverable strain gradually decreases and the specimen becomes more brittle. When the $\mathrm{Ti}_{50} \mathrm{Ni}_{25} \mathrm{Cu}_{25}$ ribbon is annealed at $500{ }^{\circ} \mathrm{C}$ for $3 \mathrm{~h}$, the specimen becomes very fragile and fractures during the tensile test.
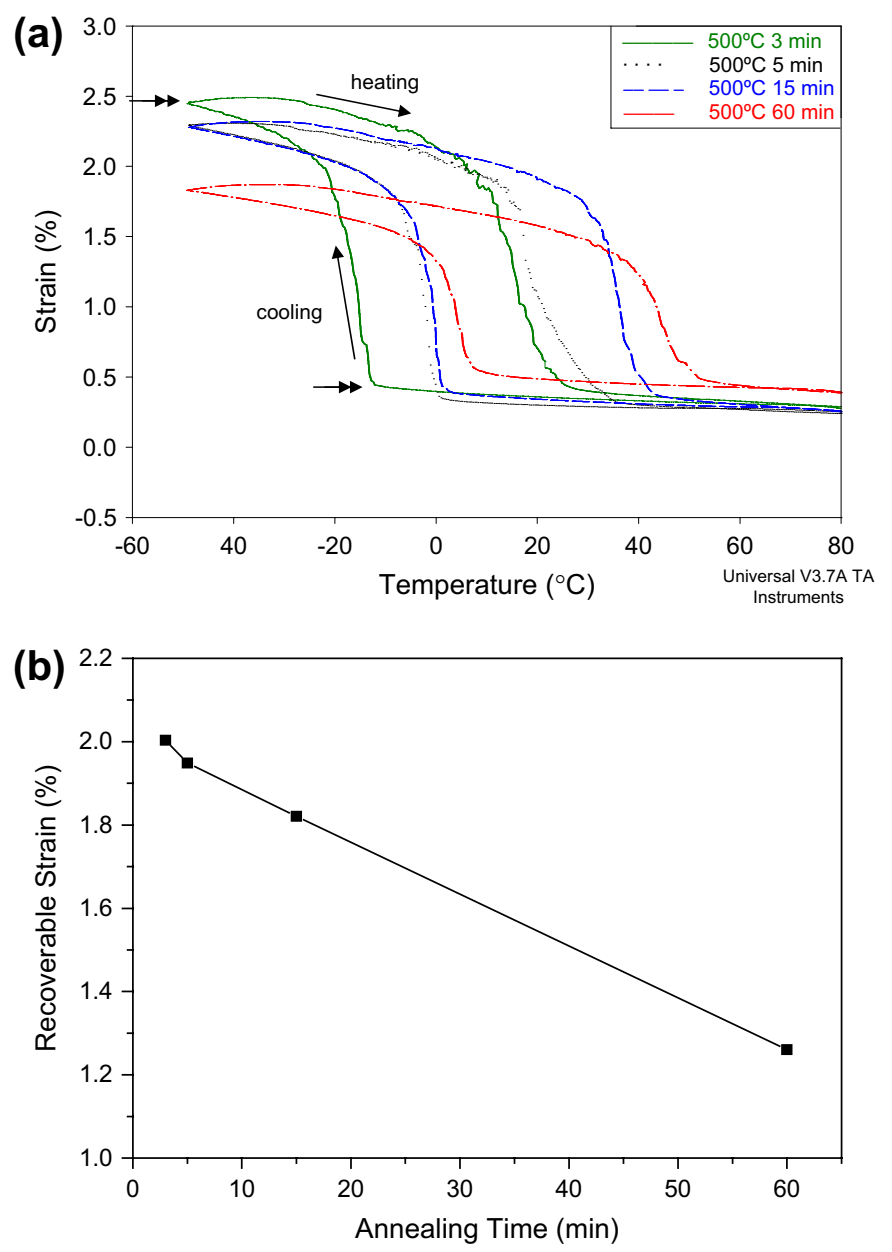

Fig. 9. (a) Thermally induced shape recovery curve under a constant stress (90 MPa) for $\mathrm{Ti}_{50} \mathrm{Ni}_{25} \mathrm{Cu}_{25}$ melt-spun ribbon annealed at $500{ }^{\circ} \mathrm{C}$ for different time intervals and (b) change of the recoverable strain value as a function of the annealing time.

\section{Discussion}

\subsection{Amorphous characteristics of $\mathrm{Ti}_{50} \mathrm{Ni}_{25} \mathrm{Cu}_{25}$ melt-spun ribbon}

As shown in Fig. 2, the $Q_{\mathrm{P}}$ values of sputtered $\mathrm{Ti}_{x} \mathrm{Ni}_{1-x}$ amorphous films are very close to the line fitted for those of melt-spun $\mathrm{Ti}_{x} \mathrm{Ni}_{1-x}$ amorphous ribbons and mechanically alloyed $\mathrm{Ti}_{x} \mathrm{Ni}_{1-x}$ powders. However, the $Q_{\mathrm{P}}$ value of $\mathrm{Ti}_{50-}$ $\mathrm{Ni}_{25} \mathrm{Cu}_{25}$ melt-spun ribbons calculated in this study, and also that of sputtered $\mathrm{Ti}_{49.96} \mathrm{Ni}_{40.09} \mathrm{Cu}_{9.95}$ films [19], is lower than those of the amorphous $\mathrm{Ti}_{x} \mathrm{Ni}_{1-x}$ SMAs deviating from the fitted line. The wavenumber $Q_{\mathrm{P}}$ is inversely proportional to the mean nearest-neighbor distance of the local-ordering clusters of the amorphous alloys. This indicates that the addition of $\mathrm{Cu}$ to replace $\mathrm{Ni}$ in $\mathrm{Ti}-\mathrm{Ni}$ binary SMAs changes the short range ordering of the amorphous phase, though the size of $\mathrm{Cu}$ atom $\left(r_{\mathrm{Cu}}=0.1413 \mathrm{~nm}\right)$ is close to that of $\mathrm{Ni}$ atom $\left(r_{\mathrm{Ni}}=0.1377 \mathrm{~nm}\right)$. In other words, the atomic arrangement of the local cluster both in the $\mathrm{Ti}_{50} \mathrm{Ni}_{25} \mathrm{Cu}_{25}$ melt-spun ribbon and in the $\mathrm{Ti}_{49.96} \mathrm{Ni}_{40.09} \mathrm{Cu}_{9.95}$ sputtered film is looser than that in $\mathrm{Ti}_{x} \mathrm{Ni}_{1-x}$ SMAs. Therefore, the average bonding strength for the local cluster in $\mathrm{Ti}-\mathrm{Ni}-\mathrm{Cu}$ ribbon/film is weaker than that in $\mathrm{Ti}_{x} \mathrm{Ni}_{1-x}$. Furthermore, as illustrated in Fig. 2, the $\mathrm{Ti}_{50} \mathrm{Ni}_{25} \mathrm{Cu}_{25}$ ribbon exhibits a lower $Q_{\mathrm{P}}$ value than the $\mathrm{Ti}_{49.96} \mathrm{Ni}_{40.09} \mathrm{Cu}_{9.95}$ film. This feature indicates that a $\mathrm{Ti}_{50-}$ $\mathrm{Ni}_{25} \mathrm{Cu}_{25}$ ribbon with a higher $\mathrm{Cu}$ content than a $\mathrm{Ti}_{49.96-}$ $\mathrm{Ni}_{40.09} \mathrm{Cu}_{9.95}$ film can exhibit looser bonding in the amorphous phase.

As shown in Fig. 4, the $E_{\mathrm{a}}$ value for $\mathrm{Ti}_{50} \mathrm{Ni}_{25} \mathrm{Cu}_{25}$ melt-spun ribbon is calculated as $341 \mathrm{~kJ} / \mathrm{mol}$. The $E_{\mathrm{a}}$ and $T_{x}$ values for $\mathrm{Ti}_{50} \mathrm{Ni}_{50}$ melt-spun ribbon are also measured in this study as $430 \mathrm{~kJ} / \mathrm{mol}$ and $522{ }^{\circ} \mathrm{C}$ (for $30^{\circ} \mathrm{C} / \mathrm{min}$ heating rate), respectively [22]. Fig. 5 indicates that $T_{x}$ for a $\mathrm{Ti}_{50} \mathrm{Ni}_{25} \mathrm{Cu}_{25}$ ribbon is about $40{ }^{\circ} \mathrm{C}$ lower than that for a $\mathrm{Ti}_{50} \mathrm{Ni}_{50}$ ribbon. Both $T_{x}$ and $E_{\mathrm{a}}$ are important indicators of the thermal stability of amorphous material, i.e., the lower values of $T_{x}$ and $E_{\mathrm{a}}$ represent the lower stability of the amorphous phase [23]. As shown in Fig. 5, $T_{x}$ of the mechanically alloyed powder is the lowest among those of sputtered thin films and melt-spun ribbons. The lowest level of amorphous stability of the mechanically alloyed powder may have been due to hydrogen contamination [16] and the large number of defects introduced during the mechanical alloying process.

As is also apparent from Figs. 4 and 5, all $\mathrm{Ti}-\mathrm{Ni}-\mathrm{Cu}$ specimens have lower $T_{x}$ and $E_{\mathrm{a}}$ values than Ti-Ni binary SMAs in both sputtered films and melt-spun ribbons. This feature indicates that the replacement of $\mathrm{Ni}$ by $\mathrm{Cu}$ indeed lowers the thermal stability of the amorphous phase and assists in crystallization occurring. Chen and Park [24] demonstrated that the stability of an amorphous alloy is dominated by the strength of the interactions between the constituent atoms. The relative strength of the interactions between different constituent atoms can be determined by comparing their mixing enthalpies. Different constituents have a stronger tendency to form an amorphous alloy when they have a larger negative mixing enthalpy [25]. Previous studies have revealed that 
$\mathrm{Ti}-\mathrm{Ni}$ has a larger negative enthalpy than $\mathrm{Ti}-\mathrm{Cu}$, and $\mathrm{Ni}-\mathrm{Cu}$ even has a positive enthalpy of mixing [26,27]. Therefore, the interaction strength between $\mathrm{Ti}$ and $\mathrm{Ni}$ atoms is stronger than that of the interaction strength between $\mathrm{Ti}$ and $\mathrm{Cu}$, and the interaction between $\mathrm{Ni}$ and $\mathrm{Cu}$ is the weakest. As a result, the amorphous alloy becomes less stable when $\mathrm{Cu}$ atoms are partially substituted for the $\mathrm{Ni}$ in $\mathrm{Ti}-\mathrm{Ni}$ binary SMAs because the average bonding strength between the atoms is decreased. Consequently, the $\mathrm{Ti}-\mathrm{Ni}-\mathrm{Cu}$ ribbon has lower $T_{x}$ and $E_{\mathrm{a}}$ values than those of $\mathrm{Ti}_{50} \mathrm{Ni}_{50}$ ribbon because the latter has a stronger tendency to form an amorphous structure.

\subsection{Crystallization of annealed $\mathrm{Ti}_{50} \mathrm{Ni}_{25} \mathrm{Cu}_{25}$ melt-spun ribbon}

\subsubsection{Annealing effect on the crystallization}

As demonstrated in Fig. 1, the as-spun $\mathrm{Ti}_{50} \mathrm{Ni}_{25} \mathrm{Cu}_{25}$ ribbon is completely amorphous. Fig. 6 reveals that the crystallized degree of the $\mathrm{Ti}_{50} \mathrm{Ni}_{25} \mathrm{Cu}_{25}$ ribbon can be controlled by the annealing time. As can be seen from Figs. 7-9, DSC and tensile test results also show that the annealing condition significantly influences the shape memory behavior of the crystallized ribbon. Both the transformation temperature and enthalpy detected in the DSC test increase with a prolonged annealing time due to an increase in the crystallization volume. However, as illustrated in Fig. 9, with an increase in the annealing time, the crystallized ribbon loses recoverable strain and simultaneously becomes brittle. In order to disclose the characteristics of these annealing effects, SEM observation with EDS analysis for the crystallized $\mathrm{Ti}_{50} \mathrm{Ni}_{25} \mathrm{Cu}_{25}$ ribbon was conducted.

Fig. 10(a)-(d) shows SEM micrographs of $\mathrm{Ti}_{50} \mathrm{Ni}_{25} \mathrm{Cu}_{25}$ ribbon annealed at $500{ }^{\circ} \mathrm{C}$ for $1 \mathrm{~min}, 3 \mathrm{~min}, 15 \mathrm{~min}$ and $3 \mathrm{~h}$, respectively. As shown in Fig. 10(a), there are some spherical particles with a diameter of about $10 \mu \mathrm{m}$ embedded in the amorphous matrix. The specimen annealed at $500{ }^{\circ} \mathrm{C}$ for 1 min does not show any crystallized peak for the XRD measurement in Fig. 6. This means that these spherical particles are not crystallized grains but are rather small bubbles produced during the melt-spinning technique retained in the amorphous matrix following the rapid solidification process [12]. The boundaries between these spherical particles and the amorphous matrix can act as nucleation sites of the crystallized grains during annealing. When the specimen is annealed at $500{ }^{\circ} \mathrm{C}$ for $3 \mathrm{~min}$, as illustrated in Fig. 10(b), some small crystallized grains with diameters of $1-3 \mu \mathrm{m}$ appear in these spherical particles. As shown in Fig. 10(c) and (d), there are more crystallized grains that developed within a prolonged annealing time interval and, therefore, the area of the amorphous matrix is reduced. Table 1 lists the EDS analyses for the chemical composition of points $1-8$ denoted in Fig. 10. As depicted in point 1 of Table 1 , the $\mathrm{Cu}$ content in the small bubble is 22.9 at.\% which is slightly less than 25 at. $\%$ when the ribbon is annealed at $500{ }^{\circ} \mathrm{C}$ for $1 \mathrm{~min}$. After annealing for $3 \mathrm{~min}$, however, the $\mathrm{Cu}$ percent of the as-crystallized grains drops to only about 16.6 at.\%, as shown in point 3 of Table 1 . This phenomenon reveals that the as-crystallized grains contain a much lower $\mathrm{Cu}$ content than the amorphous
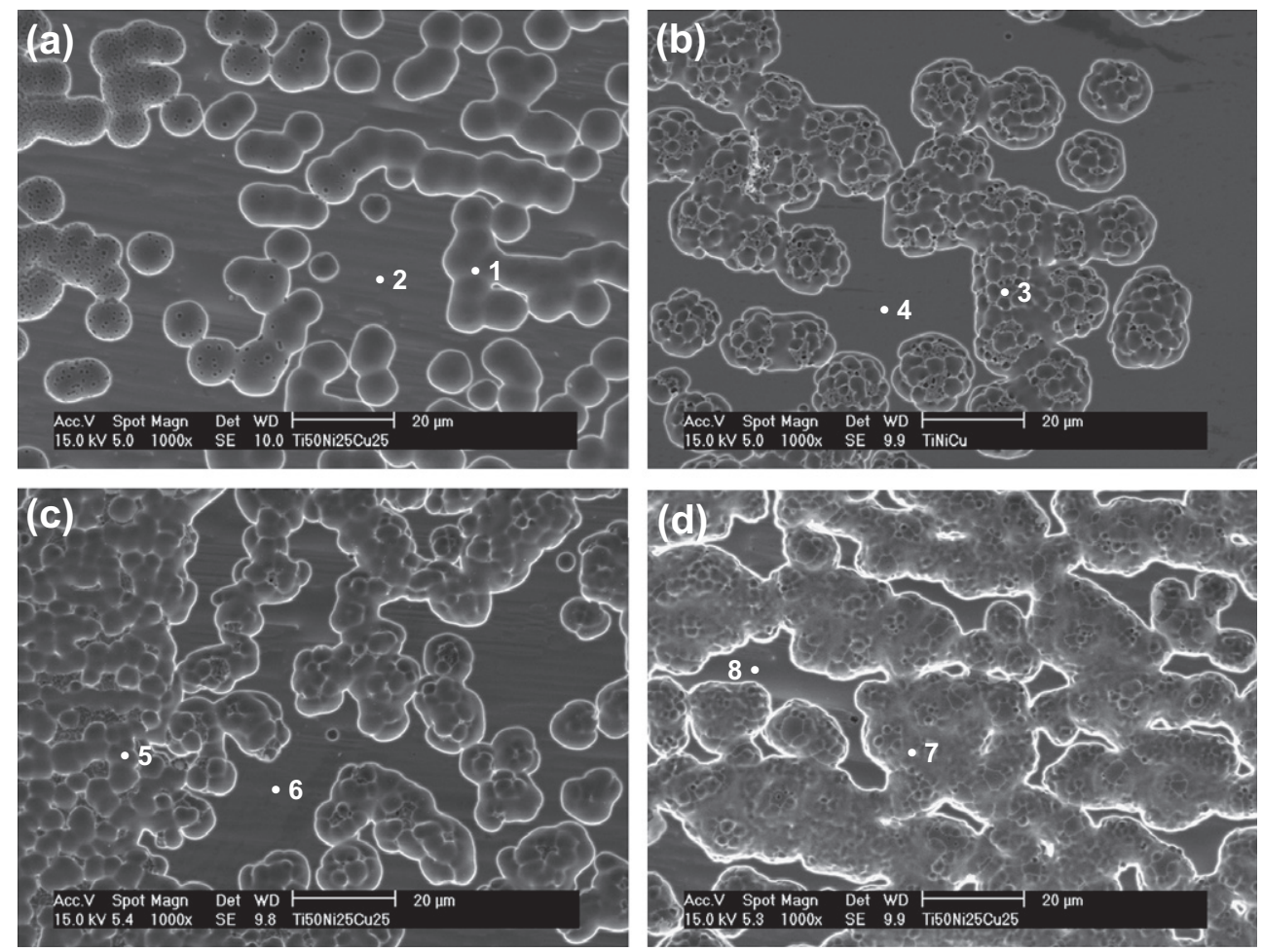

Fig. 10. SEM micrographs of $\mathrm{Ti}_{50} \mathrm{Ni}_{25} \mathrm{Cu}_{25}$ melt-spun ribbon annealed at $500{ }^{\circ} \mathrm{C}$ for (a) $1 \mathrm{~min}$ (b) $3 \mathrm{~min}$ (c) $15 \mathrm{~min}$ and (d) $3 \mathrm{~h}$. 
Table 1

EDS analyses for the chemical composition of points $1-8$ denoted in Fig. 10

\begin{tabular}{|c|c|c|c|c|}
\hline \multirow[t]{2}{*}{ Location } & \multicolumn{4}{|c|}{ Composition } \\
\hline & $\mathrm{Ti}($ at. $\%)$ & $\mathrm{Ni}$ (at.\%) & $\mathrm{Cu}($ at.\%) & Remark \\
\hline Point 1 & 52.07 & 25.01 & 22.92 & Bubble \\
\hline Point 2 & 48.22 & 24.86 & 26.91 & Amorphous \\
\hline Point 3 & 54.51 & 28.88 & 16.61 & Grain \\
\hline Point 4 & 49.29 & 24.97 & 25.74 & Amorphous \\
\hline Point 5 & 51.72 & 24.85 & 23.43 & Grain \\
\hline Point 6 & 48.55 & 27.38 & 24.07 & Amorphous \\
\hline Point 7 & 50.04 & 25.15 & 24.81 & Grain \\
\hline Point 8 & 49.29 & 24.97 & 25.74 & Amorphous \\
\hline
\end{tabular}

matrix. Through prolonging the annealing time to $15 \mathrm{~min}$, the $\mathrm{Cu}$ content in the crystallized grains raises to about 23.4 at.\%, as indicated in point 5 of Table 1 . After annealing at $500{ }^{\circ} \mathrm{C}$ for $3 \mathrm{~h}$, as shown in points 7 and 8 of Table 1, the compositions of the crystallized grains and the amorphous matrix are almost the same. This reveals that sufficient annealing can result in a homogeneously crystallized $\mathrm{Ti}_{50} \mathrm{Ni}_{25} \mathrm{Cu}_{25}$ ribbon.

From Fig. 6, the only XRD peak obtained in the as-crystallized ribbon annealed at $500{ }^{\circ} \mathrm{C}$ for $90 \mathrm{~s}$ is $(200)_{\mathrm{B} 2}$ and the lattice parameter of B2 parent phase is $0.305 \mathrm{~nm}$. This characteristic indicates that the as-crystallized grains have a fiber texture $\langle 100\rangle$ along the normal direction of the ribbon [28]. The high $\langle 100\rangle$ texture of the crystallized grains perpendicular to the ribbon surface is due to the heat flow associated with ribbon processing which is normal to the spin wheel during the rapid solidification process. This result is similar to that of the orientation distribution function (ODF) obtained in the $\mathrm{Ti}_{50} \mathrm{Ni}_{25} \mathrm{Cu}_{25}$ melt-spun ribbon $[28,29]$. Through prolonging the annealing time, however, the intensity of the $(110)_{\mathrm{B} 2}$ peak which is widely obtained in most $\mathrm{Ti}-\mathrm{Ni}-\mathrm{Cu}$ bulk alloys [5] drastically increases and becomes the dominant peak. After sufficient annealing, i.e., $500^{\circ} \mathrm{C}$ for $3 \mathrm{~h}$, the XRD pattern and the lattice parameter of the B2 parent phase $(a=0.304 \mathrm{~nm})$ are similar to those reported by Santamarta et al. [30]. Nam et al. [31] pointed out that the $\mathrm{Cu}$ content in bulk $\mathrm{Ti}-\mathrm{Ni}-\mathrm{Cu}$ SMAs does indeed affect the lattice parameter of the parent phase and therefore changes their transformation elongation. Accordingly, it is reasonable to propose that the alteration of the XRD pattern and the decrease in the B2 lattice parameter shown in Fig. 6 are due to the variation of $\mathrm{Cu}$ content in crystallized grains caused by annealing.

In Fig. 10, the diameter of crystallized grains does not strongly increase as the annealing time increases. At the same time, the increase in the crystallized volume is not due to the grain growth but is associated with the formation of new grains in the amorphous matrix. This implies that the required energy for new grain nucleation in the amorphous matrix is lower than that for the grain growth of the existing crystallized grains. The supercooling amorphous state provides a high driving force for both nucleation and subsequent grain growth. However, the annealing temperature at $500{ }^{\circ} \mathrm{C}$ conducted in this study may be insufficient to promote sticky atom diffusion. This feature leads to a slow diffusion rate and limits grain growth.

\subsubsection{Annealing effect on shape memory properties}

When $\mathrm{Ti}_{50} \mathrm{Ni}_{25} \mathrm{Cu}_{25}$ ribbon is mildly annealed, as shown in Fig. 10(a), no obvious phase transformation and well-defined shape recovery can be obtained. After annealing at $500{ }^{\circ} \mathrm{C}$ for 3 min, as shown in Fig. 10(b), small crystallized grains appear. At this time, the recoverable strains reach a maximum, as indicated in Fig. 9. Through prolonging the annealing time, more crystallized grains form, as illustrated in Fig. 10(c) and (d), however, the amount of recoverable strain decreases, as shown in Fig. 9. We propose that the degenerated shape recovery effect is mainly due to the composition alteration in the crystallized grains of annealed $\mathrm{Ti}_{50} \mathrm{Ni}_{25} \mathrm{Cu}_{25}$ ribbon. The as-crystallized grains contain a lower $\mathrm{Cu}$ content and perform a prominent shape recovery effect. Through prolonging the annealing time, on the other hand, the increased $\mathrm{Cu}$ content in the crystallized grains results in brittle characteristics and a low recoverable strain. This feature is similar to the results obtained in bulk $\mathrm{Ti}-\mathrm{Ni}-\mathrm{Cu}$ alloys $[2,31]$ in which the variation in $\mathrm{Cu}$ content influences the lattice parameters of the phases and changes the recoverable strain during B2 $\leftrightarrow$ B19 transformation. Therefore, the crystallized grains in the longer annealed $\mathrm{Ti}_{50} \mathrm{Ni}_{25} \mathrm{Cu}_{25}$ ribbon contain a higher copper content which embrittles the annealed ribbon and reduces the shape recovery effect. Consequently, a $\mathrm{Ti}_{50} \mathrm{Ni}_{25} \mathrm{Cu}_{25}$ ribbon exhibits a good shape memory effect only under appropriate annealing conditions, such as annealing at $500^{\circ} \mathrm{C}$ for 3 min in this study.

\section{Conclusions}

The amorphous $\mathrm{Ti}_{50} \mathrm{Ni}_{25} \mathrm{Cu}_{25}$ melt-spun ribbons which are partially crystallized by $500{ }^{\circ} \mathrm{C}$ annealing have been investigated by means of XRD, DSC, DMA and SEM tests. As shown by the XRD results, the as-spun $\mathrm{Ti}_{50} \mathrm{Ni}_{25} \mathrm{Cu}_{25}$ ribbon is fully amorphous with the lowest wavenumber $Q_{\mathrm{p}}$ among the amorphous $\mathrm{Ti}-\mathrm{Ni}$ and $\mathrm{Ti}-\mathrm{Ni}-\mathrm{Cu}$ alloys fabricated by mechanical alloying, rapid quenching and sputter deposition. This indicates that the high $\mathrm{Cu}$ content of $\mathrm{Ti}_{50} \mathrm{Ni}_{25} \mathrm{Cu}_{25}$ ribbon can loosen the atomic bonding in the amorphous phase. The $E_{\mathrm{a}}$ value of $\mathrm{Ti}_{50} \mathrm{Ni}_{25} \mathrm{Cu}_{25}$ ribbon is $341 \mathrm{~kJ} / \mathrm{mol}$ calculated from the DSC data using Kissinger's method. The $T_{x}$ for $\mathrm{Ti}_{50-}$ $\mathrm{Ni}_{25} \mathrm{Cu}_{25}$ ribbons is about $40{ }^{\circ} \mathrm{C}$ lower than that for $\mathrm{Ti}_{50} \mathrm{Ni}_{50}$ ribbons. These characteristics indicate that the as-spun $\mathrm{Ti}_{50-}$ $\mathrm{Ni}_{25} \mathrm{Cu}_{25}$ ribbon has a lower thermal stability than $\mathrm{Ti}_{50} \mathrm{Ni}_{50}$ ribbon from the viewpoint of the mixing enthalpy. Crystallization degree in a $\mathrm{Ti}_{50} \mathrm{Ni}_{25} \mathrm{Cu}_{25}$ ribbon can be controlled by appropriate annealing. When a $\mathrm{Ti}_{50} \mathrm{Ni}_{25} \mathrm{Cu}_{25}$ ribbon is annealed at $500{ }^{\circ} \mathrm{C}$ for less than $1 \mathrm{~min}$, no obvious phase transformation and well-defined shape recovery can be obtained. When a $\mathrm{Ti}_{50-}$ $\mathrm{Ni}_{25} \mathrm{Cu}_{25}$ ribbon is annealed at $500{ }^{\circ} \mathrm{C}$ for $3 \mathrm{~min}$, the initial as-crystallized grains contain a lower $\mathrm{Cu}$ content than the amorphous matrix, but they exhibit a prominent shape memory effect. Through prolonging the annealing time, more grains are nucleated and the $\mathrm{Cu}$ content in the crystallized grains gradually increases. The more the grains are crystallized, the more the annealed ribbons become fragile and, as a consequence, their recoverable strain deteriorates. This feature is related to 
the increased $\mathrm{Cu}$ content in the crystallized grains which can embrittle the annealed ribbon and influence the lattice parameters of the phases and affect the recoverable strain during the B2 $\leftrightarrow$ B19 transformation. Consequently, $\mathrm{Ti}_{50} \mathrm{Ni}_{25} \mathrm{Cu}_{25}$ ribbons can exhibit a good shape memory effect only under appropriate annealing condition.

\section{Acknowledgement}

The authors gratefully acknowledge the financial support from National Science Council (NSC), Taiwan, Republic of China, under the grant NSC93-2216-E002-003. We also sincerely acknowledge Dr. Ho-Sou Chen, a fellow of the American Physical Society, for his assistance in ribbon preparation and for his guidance in the investigation of the amorphous state performed in this study.

\section{References}

[1] Wayman CM, During TW. Engineering aspects of shape memory alloys. In: During TW, Melton KN, Stöckel D, Wayman CM, editors. London: Butterworth-Heinemam Press; 1990.

[2] Nam TH, Saburi T, Shimizu K. Mater Trans JIM 1990;31:959.

[3] Furuya Y, Matsumoto M, Kimura HS, Masumoto T. Mater Sci Eng A 1991;147:7.

[4] Tang W, Sndstrom R, Wei ZG, Miyazaki S. Metall Mater Trans 2000;31A:2423.

[5] Lo YC, Wu SK, Horng HE. Acta Metall Mater 1993;41:747.

[6] Bricknell RH, Melton KN, Mercier O. Metall Trans 1979;10A:693.
[7] Miyazaki S, Mizukoshi K, Ueki T, Sakuma T, Liu YN. Mater Sci Eng A 1999;273-275:658.

[8] Xie ZL, Van Humbeek J, Liu Y, Delaey L. Scripta Mater 1997; 37:363.

[9] Rösner H, Shelyakov AV, Glezer AM, Feit K, Schloßmacher P. Mater Sci Eng A 1999;273-275:733.

[10] Satto C, Ledda A, Potapov P, Janssens JF, Schryvers D. Intermetallics 2001;9:395.

[11] Rösner H, Schloßmacher P, Shelyakov AV, Glezer AM. Acta Mater 2001;49:1541.

[12] Santamarta R, Schryvers D. Mater Trans 2003;44:1760.

[13] Santamarta R, Cesari E, Pons J, Goryczka T. Metall Mater Trans 2004;35A:761.

[14] Liu Y. Mater Sci Eng A 2003;354:286.

[15] Cheng GP, Xie ZL. J Alloys Compd 2005;396:128.

[16] Eckert J, Schultz L. J Non-Cryst Solids 1991;127:90.

[17] Buschow KH. J Phys 1983;F13:563.

[18] Chen JZ, Wu SK. Thin Solid Films 1999;339:194.

[19] Chen JZ, Wu SK. J Non-Cryst Solids 2001;288:159.

[20] Seeger C, Ryder PL. Mater Sci Eng A 1994;179-180:641.

[21] Kissinger HE. Anal Chem 1957;29:1702.

[22] Chang SH, Wu SK, Kimura H. Private communication; 2005.

[23] Dong YD, Gergan G, Scott MG. J Non-Cryst Solids 1981;43:403.

[24] Chen HS, Park BK. Acta Metall 1973;21:395.

[25] Chen HS. Acta Metall 1974;22:897.

[26] Weeber AW, Bakker H. Physica B 1988;153:93.

[27] Miedema AR. Philips Tech Rev 1976;36:217.

[28] Santamarta R, Cesari E, Pons J, Goryczka T. Metall Mater Trans 2004;35A:761.

[29] Khantachawana A, Mizubayashi H, Miyazaki S. Mater Trans 2004; $45: 214$

[30] Santamarta R, Pons J, Cesari E. J Phys IV France 2001;11:351.

[31] Nam TH, Saburi T, Nakata Y, Shimizu K. Mater Trans JIM 1990;31:1050. 